\title{
Implementasi Aplikasi Business Intelligence Untuk Memonitor Efisiensi Pengelolaan Rumah Sakit
}

\author{
Herwanto, Ali Khumaidi* \\ Fakultas Teknik, Program Studi Teknik Informatika, Universitas Krisnadwipayana, Jakarta, Indonesia \\ Email: ${ }^{1}$ Herwanto@unkris.ac.id, ${ }^{2}$ alikhumaidi@unkris.ac.id \\ Email Penulis Korespondensi: alikhumaidi@unkris.ac.id
}

\begin{abstract}
Abstrak-Kebutuhan informasi yang cepat dan akurat sudah menjadi kebutuhan setiap perusahaan termasuk rumah sakit. Hal tersebut merupakan salah satu faktor yang membuat perusahaan lebih unggul dari perusahaan lain. Dalam membuat keputusan yang tepat dan akurat, para pimpinan membutuhkan informasi yang disajikan dengan jelas, mudah dimengerti, tepat waktu, dan sesuai dengan kebutuhan. Untuk mendukung penyajian informasi seperti itu dibutuhkan database, data warehouse, dan aplikasi lain yang mudah dipahami. Rumah Sakit sebagai lembaga sosio-ekonomi selain dituntut untuk memberikan solusi atas persoalan kesehatan juga dituntut untuk selalu meningkatkan mutu pelayanannya. Agar tujuan tersebut tercapai, pengelolaannya harus efisien. Indikator pelayanan dapat digunakan sebagi alat ukur untuk menilai tingkat efisiensi pengelolaan. Aplikasi Business Intelligence (BI) merupakan salah satu bentuk implementasi yang mampu memudahkan manajemen untuk memonitor kinerja rumah sakit.Penelitian ini menggali penggunaan teknologi informasi untuk membangun aplikasi BI, meninjau pendekatan yang tepat dalam membangun aplikasi BI, serta beberapa aspek penting yang harus dipertimbangkan agar sistem bekerja untuk lingkungan rumah sakit. Terdapat dua tahapan utama dalam membangun aplikasi ini, yaitu: membangun data warehouse yang berasal dari database rekam medis elektronik dan operasional rumah sakit, serta membangun aplikasi BI. Dengan terbentuknya aplikasi BI ini, sangat berguna bagi manajemen rumah sakit dalam mengelola institusinya dengan lebih baik.
\end{abstract}

Kata Kunci: Data Warehouse, Indikator Pelayanan, Business Intelligence, Aplikasi, Monitoring

Abstract-The need for fast and accurate information has become the need of every company, including hospitals. This is one of the factors that makes a company superior to other companies. In making the right and accurate decisions, leaders need information that is presented clearly, easily understood, on time, and in accordance with needs. To support the presentation of such information a database, data warehouse and other applications that are easy to understand are needed. Hospitals as a socio-economic institution are not only required to provide solutions to health problems but are also demanded to always improve the quality of their services. For this purpose to be achieved, its management must be efficient. Service indicators can be used as a measuring tool to assess the level of management efficiency. Business Intelligence (BI) application is one form of implementation that is able to facilitate management to monitor hospital performance. This research explores the use of information technology to build BI applications, reviewing the right approach in building BI applications, as well as several important aspects that must be considered for the system work for the hospital environment. There are two main stages in building this application, namely: building a data warehouse originating from an electronic medical record database and hospital operations, and building a BI application. With the formation of this BI application, it is very useful for hospital management in managing their institutions better.

Keywords: Data Warehouse, Service Indicator, Business Intelligence, Application, Monitoring

\section{PENDAHULUAN}

Perkembangan teknologi informasi dan telekomunikasi yang begitu pesat mampu memberikan nilai tambah yang sangat besar kepada berbagai bidang termasuk di sektor pelayanan kesehatan (rumah sakit). Namun bila dibandingkan dengan sektor lain, penerapan teknologi informasi di rumah sakit relatif tertinggal[1]. Sebagai contoh, ketika transaksi keuangan secara elektronik sudah menjadi salah satu prosedur standar dalam dunia perbankan, sebagian besar rumah sakit di Indonesia baru dalam tahap pengembangan billing system. Padahal perkembangan teknologi kedokteran dan kebijakan untuk rumah sakit terus berubah dan berkembang pesat.

Dalam upaya untuk memberikan pelayanan kesehatan semaksimal mungkin kepada masyarakat, rumah sakit disamping dituntut untuk dapat memberikan solusi atas persoalan kesehatan juga dituntut untuk selalu meningkatkan mutu pelayanannya[2]. Salah satu jawaban untuk mendukung tujuan diatas adalah diterapkannya sistem informasi manajemen rumah sakit yang mampu mengadministrasikan seluruh kegiatan pelayanan sehingga dapat meningkatkan kinerja seluruh organisasi di dalam rumah sakit.

Saat ini komputerisasi di sebagian besar rumah sakit sudah merupakan bagian yang tidak terpisahkan dari kegiatan operasionalnya[3]. Hal ini dikarenakan proses bisnis yang ada cukup kompleks, beragam kegiatan yang harus dilakukan dan melibatkan beragam latar belakang profesi yang menjalankannya. Manajemen rumah sakit sangat berkepentingan didalam melakukan pengawasan terhadap proses bisnisnya, sedangkan pasien/pelanggan menuntut adanya transparansi serta akurasi dari jasa yang dibayar[4]. Dapat dibayangkan apa yang akan terjadi apabila pengawasan terhadap kegiatan tersebut tidak didukung oleh suatu sistem yang dapat dipertanggungjawabkan akurasi data dan ketepatan waktunya.

Indikator pelayanan rumah sakit merupakan bagian dari salah satu statistik rumah sakit. Dengan adanya indikator tersebut dapat mengetahui tingkat pemanfaatan, mutu serta efisiensi pelayanan yang terdapat di rumah sakit. Indikator pelayanan tersebut bersumber dari data sensus harian rawat inap. Ada empat indikator yang dapat digunakan, yaitu[5]: Rata-rata lama rawat atau Length of Stay (LOS), Rata-rata waktu tunggu luang tempat tidur 
terisi atau Turnover Interval, Persentasi tempat tidur terisi atau Percentage Bed Occupation dan Produktifitas tempat tidur atau Bed Turnover Rate atau Throughput.

Basis data rumah sakit yang dihasilkan dari sistim informasi rumah sakit umumnya berisi data dalam jumlah besar.Menyaring serta menyajikan informasi-informasi yang relevan dalam basis data yang besar ini adalah pekerjaan yang rumit[6][7]. Sehingga perlu teknik-teknik tertentu agar proses penyaringan informasi bisa dilakukan secara efisien dan efektif, antara lain dengan menerapkan data warehouse yang akan berfungsi sebagai pusat penyimpanan data yang terintegrasi sebagai hasil penyaringan data operasional[8][9]. Data warehouse adalah kumpulan data yang subject oriented, integrated, nonvolatile dan time variant untuk membantu membuat keputusan manajemen[10]. Star schema adalah jenis perancangan basis data yang digunakan untuk mendukung analytical processing. Star schema berisi dua jenis tabel yaitu tabel fakta dan tabel dimensi. Tabel fakta atau disebut juga major table berisi data kuantitatif atau data transaksi sesungguhnya yang ada pada organisasi dimana informasi yang ada didalamnya akan dianalisa. Informasi ini biasanya berupa pengukuran numerikal dan bisa terdiri dari banyak kolom dan jutaan baris. Tabel dimensi atau disebut juga minor table, berisi deskripsi data yang merefleksikan dimensi organisasi[11]. Perancangan basis data dengan mengunakan star schema ini paling banyak digunakan untuk membangun struktur data pada data mart dalam lingkungan relasional[12].

Business Intelligence (BI) merupakan sebuah proses untuk melakukan ekstraksi data-data operasional perusahaan dan mengumpulkannya dalam sebuah data warehouse. Selanjutnya data warehouse diproses menggunakan berbagai analisis statistik, sehingga didapat berbagai kecenderungan atau pattern dari data[13]. Hasil penyederhanaan dan peringkasan ini disajikan kepada end user yang umumnya merupakan pengambil keputusan bisnis. Dengan BI data diringkas menjadi laporan untuk berbagi informasi dengan orang di dalam dan di luar organisasi[14]. Dengan demikian manajemen dapat mengambil keputusan berdasarkan fakta-fakta aktual, dan tidak hanya mengandalkan intuisi dan pengalaman kuantitatif saja[15].

Dengan menggunakan teknologi informasi maka alur bisnis dapat dipantau melalui rekaman seluruh proses, sejak pasien berinteraksi dengan layanan pendaftaran, berinteraksi dengan dokter baik di layanan rawat jalan maupun di gawat darurat; berinteraksi dengan sarana penunjang medik seperti laboratorium, radiologi, rehabilitasi medik, farmasi, berinteraksi dengan sarana rawat inap, dan lainnya. Perekaman tersebut untuk memenuhi kebutuhan sistem pelaporan kegiatan dan statistik maupun untuk kepentingan pencatatan transaksi keuangan. Untuk mengukur tingkat efisiensi pengelolaan rumah rumah sakit diperlukan indikator pelayanan rumah sakit.Dengan adanya indikator tersebut dapat mengetahui tingkat pemanfaatan, mutu serta efisiensi pelayanan yang terdapat di rumah sakit[16]. Penelitian ini berfokus pada penerapan aplikasi BI yang digunakan untuk memudahkan manajemen dalam memonitor efisiensi pengelolaan rumah sakit.

\section{METODE PENELITIAN}

Kegiatan penelitian ini dilakukan dengan tiga tahapan utama, yaitu proses konsolidasi data, pembangunan data warehouse, dan pembuatan aplikasi BI. Proses pembangunan aplikasi BI dilakukan berdasarkan urutan proses pada Gambar 1.

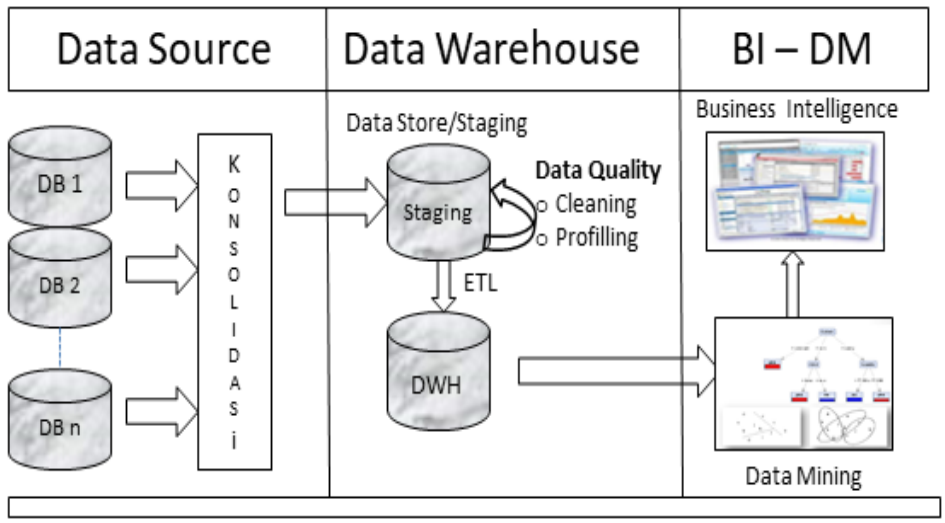

Gambar 1. Proses Pembangunan Aplikasi BI

Sumber data yang digunakan dalam penelitian ini bersumber dari sistem informasi yang ada di beberapa rumah sakit dan menggunakan database dari vendor yang berbeda-beda.Dengan kondisi teknologi basis data yang berlainan, sehingga diperlukan tahapan konsolodasi data agar bisa menyajikan informasi yang beragam menjadi satu kesatuan informasi. Proses konsolidasi data dilakukan dengan menggunakan Open Database Connectivity (ODBC).

Data warehouse bukan prasyarat untuk aplikasi BI, tetapi dalam prakteknya pembangunan aplikasi BI dibuat lebih mudah dengan mengakses dari data warehouse. Dalam penelitiaan ini arsitektur yang digunakan untuk pembangunan data warehouse adalah arsitektur data warehouse dengan menggunakan staging area. 
Dimana data warehouse yang dirancang, akan dimulai dari pengumpulan data di tingkat operasional. Datadata tersebut dikumpulkan di staging area. Setelah data masuk dalam staging area, selanjutnya dilakukan proses Extract, Transform, dan Load (ETL).

ETL merupakan proses yang sangat penting dalam data warehouse, dengan ETL inilah data dari operasional dapat dimasukkan ke dalam data warehouse. ETL juga dapat digunakan untuk mengintegrasikan data dengan sistem yang sudah ada sebelumnya. Hasil dari proses ETL adalah dihasilkannya data yang memenuhi kriteria data warehouse seperti data yang historis, terpadu, terangkum, statis, dan memiliki struktur yang dirancang untuk keperluan proses analisis.

Data yang sudah terkumpul dalam data warehouse selanjutnya dilakukan proses analisis menggunakan aplikasi BI. Aplikasi BI yang dibangun terdiri dari dua elemen utama, yaitu dataset yang akan dianalisa oleh user: Yang merupakan backend dari aplikasi BI dan berisi seluruh source tables yang diperlukan untuk membangun data model. Serta user interface yang merupakan frontend aplikasi analitik dan berisi objek-objek yang dikandung dalam dokumen (seperti listbox untuk membuat pilihan dan filter data), atau grafik dan tabel yang digunakan untuk menampilkan informasi.

\section{HASIL DAN PEMBAHASAN}

Pembangunan aplikasi BI dalam penelitian ini menggunakan software Qlikview personal edition yang bisa di download secara gratis dari website Qlikview. Software ini mempunyai kemampuan untuk melakukan data analysis, membuat dashboard dan report. Kebutuhan aplikasi BI pada penelitian ini untuk memonitor tingkat efisiensi pengelolaan rumah sakit yang dilihat dari dua segi, yaitu segi medis meninjau efisiensi dari sudut mutu pelayanan medis dan dari segi ekonomi meninjau efisiensi dari sudut pendayagunaan sarana yang ada. Terdapat empat parameter yang diukur sebagai salah satu indikator efisiensi rumah sakit, yaitu: Rata-rata lama rawat atau Length of Stay (LOS), Rata-rata waktu tunggu luang tempat tidur terisi atau Turnover Interval, Persentasi tempat tidur terisi atau Percentage Bed Occupation, dan Produktifitas tempat tidur atau Bed Turnover Rate atau Throughput. Pada saat yang sama, aplikasi harus memungkinkan pengguna untuk memilih dimensi rumah sakit, yaitu ruang perawatan, jenis penyakit, serta periode laporan.

\section{Menghitung Rata-rata Length of Stay (AvLOS)}

AvLOS menurut Depkes RI adalah rata-rata lama rawat seorang pasien. Indikator ini disamping memberikan gambaran tingkat efisiensi, juga dapat memberikan gambaran mutu pelayanan, apabila diterapkan pada diagnosis tertentu dapat dijadikan hal yang perlu pengamatan yang lebih lanjut.Rata-rata lama perawatan ini menggambarkan rata-rata lama rawat inap pasien yang dipulangkan selama periode tersebut. Atau rata-rata lama dirawat seorang pasien. AvLOS merupakan total lamanya dirawat. Secara umum nilai AVLOS yang ideal antara 6-9 hari[5]. Untuk menghitung length of stay per tahun dilakukan dengan menggunakan rumus:

$$
\text { AvLOS }=0 \text { x 365/D }
$$

Keterangan:

$\mathrm{O}=$ Rata-rata tempat tidur yang terisi.

$\mathrm{D}=$ jumlah pasien yang keluar.

Untuk mendapatkan nilai O, setiap hari pada jam 24 dilakukan rekapitulasi tempat tidur yang terisi di setiap bangsal ruang perawatan. Nilai D didapat dengan menghitung jumlah pasien yang keluar dalam keadaan hidup atau meninggal setiap hari dari tiap-tiap bangsal/ruang perawatan.

\section{Menghitung Turnover Interval (TOI)}

TOI adalah rata-rata hari dimana tempat tidur tidak ditempati dari telah diisi ke saat terisi berikutnya. Angka TOI menunjukkan rata-rata jumlah hari sebuah tempat tidur (Bed) tidak ditempati untuk perawatan pasien. Hari "kosong" ini terjadi antara saat bed ditinggalkan oleh seorang pasien hingga digunakan lagi oleh pasien berikutnya. Indikator ini memberikan gambaran tingkat efisiensi penggunaan tempat tidur.Idealnya tempat tidur kosong tidak terisi pada kisaran 1-3 hari[5].Untuk menghitung TOI per tahun dilakukan dengan menggunakan rumus:

$$
\text { TOI }=(\mathrm{A}-\mathrm{O}) \times 365 / \mathrm{D}
$$

Keterangan:

$\mathrm{A}=$ Kapasitas bed yang siap pakai

$\mathrm{O}=$ Rata-rata tempat tidur yang terisi

$\mathrm{D}=$ Jumlah pasien yang keluar 


\section{JURNAL MEDIA INFORMATIKA BUDIDARMA}

Volume 4, Nomor 3, Juli 2020, Page 495-502

ISSN 2614-5278 (media cetak), ISSN 2548-8368 (media online)

Available Online at https://ejurnal.stmik-budidarma.ac.id/index.php/mib

DOI 10.30865/mib.v4i3.2090

\section{Menghitung Percentage Bed Occupacy Rate (BOR)}

BOR menurut Depkes RI adalah prosentase pemakaian tempat tidur pada satuan waktu tertentu. Indikator ini memberikan gambaran tinggi rendahnya tingkat pemanfaatan tempat tidur rumah sakit. Nilai parameter BOR yang ideal adalah antara 60-85\%[5]. Untuk menghitung BOR dilakukan dengan menggunakan rumus:

$$
\text { BOR }=\text { O x 100/A }
$$

Keterangan:

$\mathrm{O}=$ Rata-rata tempat tidur yang terisi

A = Kapasitas bed yang siap pakai

\section{Menghitung Bed Turnover (BTO)}

BTO adalah frekuensi pemakaian tempat tidur pada satu periode, berapa kali tempat tidur dipakai dalam satu satuan waktu tertentu. Idealnya dalam satu tahun, satu tempat tidur rata-rata dipakai 40-50 kali[5]. Untuk menghitung BTO dilakukan dengan menggunakan rumus:

$$
\text { BTO }=\text { D/A }
$$

Keterangan:

$\mathrm{D}=$ Jumlah pasien yang keluar

A = Kapasitas bed yang siap pakai

Sumber data yang digunakan untuk menghitung keempat parameter tersebut diambil dari data transaksi rumah sakit.Untuk kebutuhan aplikasi BI ini, setelah melalui proses ETL didapat dua tabel yaitu tabel Bed Siap Pakai dan tabel Transaksi Kamar. Tabel Bed Siap Pakai terdiri dari kolom Ruangan dan Kapasitas Bed. Tabel Transaksi Kamar terdiri dari kolom Tanggal Transaksi, Ruangan, Bed Terisi, Kapasitas Bed, Jumlah Pasien Keluar. Penghubung kedua tabel tersebut adalah kolom Ruangan yang didalam tabel Bed Siap Pakai sebagai Primary Key sedangkan pada tabel Transaksi Kamar sebagai Foreign Key. Contoh data diperlihatkan pada tabel 1 dan tabel 2.

Tabel 1. Bed Siap Pakai

\begin{tabular}{cc}
\hline Ruangan & Kapasitas_Bed \\
\hline 2F & 8 \\
3B & 44 \\
3F & 26 \\
3L & 16 \\
3S & 6 \\
4B & 42 \\
4F & 45 \\
5B & 25 \\
5F & 10 \\
5I & 6 \\
6B & 27 \\
6F & 20 \\
7B & 61 \\
7F & 16 \\
A2 & 28 \\
\hline
\end{tabular}

Tabel 2. Transaksi Kamar

\begin{tabular}{ccccc}
\hline Tanggal_Transaksi & Ruangan & Bed_terisi & Kapasitas_Bed & Jumlah_Pasien_Keluar \\
\hline $1 / 1 / 2013$ & 7F & 12 & 16 & 2 \\
$1 / 1 / 2013$ & $4 \mathrm{~F}$ & 16 & 45 & 1 \\
$1 / 1 / 2013$ & 4B & 20 & 42 & 3 \\
$1 / 1 / 2013$ & 5B & 16 & 25 & 1 \\
$1 / 1 / 2013$ & $3 \mathrm{~S}$ & 1 & 6 & 0 \\
$1 / 1 / 2013$ & 5F & 4 & 10 & 2 \\
$1 / 1 / 2013$ & A2 & 10 & 28 & 3 \\
$1 / 1 / 2013$ & 3F & 12 & 26 & 1 \\
$1 / 1 / 2013$ & 3L & 5 & 16 & 0 \\
$1 / 1 / 2013$ & 7B & 28 & 61 & 7 \\
$1 / 1 / 2013$ & 6B & 21 & 27 & 1 \\
$1 / 1 / 2013$ & 2F & 0 & 8 & 0 \\
$1 / 1 / 2013$ & 3B & 27 & 44 & 3 \\
\hline
\end{tabular}


JURNAL MEDIA INFORMATIKA BUDIDARMA

Volume 4, Nomor 3, Juli 2020, Page 495-502

ISSN 2614-5278 (media cetak), ISSN 2548-8368 (media online)

Available Online at https://ejurnal.stmik-budidarma.ac.id/index.php/mib

DOI $10.30865 / \mathrm{mib} . v 4 \mathrm{i} 3.2090$

\begin{tabular}{ccccc}
\hline Tanggal_Transaksi & Ruangan & Bed_terisi & Kapasitas_Bed & Jumlah_Pasien_Keluar \\
\hline $1 / 1 / 2013$ & 6F & 12 & 20 & 2 \\
$1 / 1 / 2013$ & 5I & 3 & 6 & 0 \\
$1 / 2 / 2013$ & 3B & 27 & 44 & 4 \\
$1 / 2 / 2013$ & 4F & 23 & 45 & 4 \\
$1 / 2 / 2013$ & 3L & 8 & 16 & 0 \\
$1 / 2 / 2013$ & 3F & 14 & 26 & 2 \\
$1 / 2 / 2013$ & 5F & 5 & 10 & 1 \\
$1 / 2 / 2013$ & 7F & 6 & 16 & 2 \\
$1 / 2 / 2013$ & 4B & 25 & 42 & 4 \\
$\ldots$ & $\ldots$ & $\ldots$ & $\ldots$ & $\ldots$ \\
\hline
\end{tabular}

\section{Membangun Data Model}

Jantung aplikasi QlikView adalah data model, terdiri dari berbagai source tabel yang berbeda yang berisi informasi dan data yang digunakan untuk mengukur kinerja perusahaan. Model data dibangun dengan menggunakan bahasa scripting QlikView. Sebuah model data yang dibangun dengan benar menghubungkan semua tabel yang memungkinkan kita untuk memanipulasi data sesuai keinginan. Berikut ini adalah scripting Qlikview untuk memuat data:

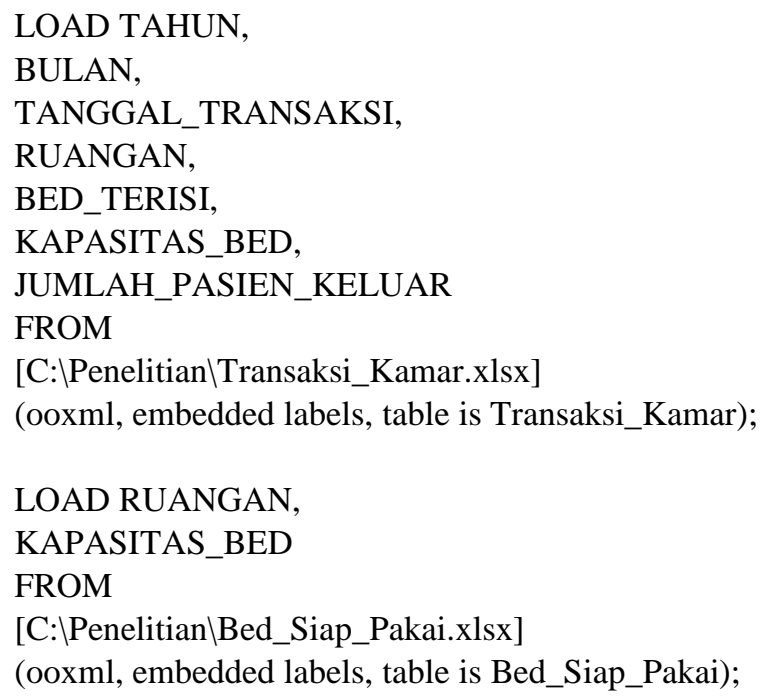

\section{Mambuat Interface}

a. Membuat List box:

Membuat 2 list box Tahun dan Bulan

Untuk membuat list box Tahun:

1) Right click on the sheet, New Sheet Object > List Box.

2) In General tab, set title as Tahun.

3) On Field dropdown box, choose Tahun.

4) Go to Presentation tab; uncheck the boxes for Single Column and Order by Column.

b. Untuk membuat list box Bulan dilakukan dengan mengulang langkah 1 sampai dengan 4

\section{Membuat sheet object}

a. Membuat sheet object Bed Occupation Rate - Bar Chart

1) Layout $>$ New Sheet Object $>$ Chart

2) At General tab, set the title of chart to 'Bed Occupation Rate - BOR' and check the Show Title in Chart.

3) Choose Bar Chart for Chart Type.

4) Move on to Dimensions tab.

5) Choose Ruangan as the dimension.

6) Move on to Expression tab.

7) Click Add

8) Enter the formula "=SUM(BED_TERISI) / SUM(KAPASITAS_BED)"

b. Membuat sheet object Length of Stay - Bar Chart 
JURNAL MEDIA INFORMATIKA BUDIDARMA

Volume 4, Nomor 3, Juli 2020, Page 495-502

ISSN 2614-5278 (media cetak), ISSN 2548-8368 (media online)

Available Online at https://ejurnal.stmik-budidarma.ac.id/index.php/mib

DOI 10.30865/mib.v4i3.2090

Untuk membuat sheet object Length of Stay dilakukan dengan mengulang langkah 1 sampai dengan 7 diatas.

8) Enter the formula "=SUM(BED_TERISI)/SUM(JUMLAH_PASIEN_KELUAR)"

c. Membuat sheet object Bed Turnover - Bar Chart

Untuk membuat sheet object Bed Turnover dilakukan dengan mengulang langkah 1 sampai dengan 7 diatas.

8) Enter the formula "=ROUND(sum(JUMLAH_PASIEN_KELUAR) /SUM(KAPASITAS_BED))"

d. Membuat sheet object Turnover Interval - Bar Chart

Untuk membuat sheet object Turnover Interval dilakukan dengan mengulang langkah 1 sampai dengan 7 diatas.
8) Enter
the
formula
$"=$ ROUND $((\operatorname{sum}($ KAPASITAS_BED $)-$
sum(BED_TERISI))/SUM(JUMLAH_PASIEN_KELUAR))"

Tampilan aplikasi dashboard diperlihatkan pada gambar 2 sampai dengan 5

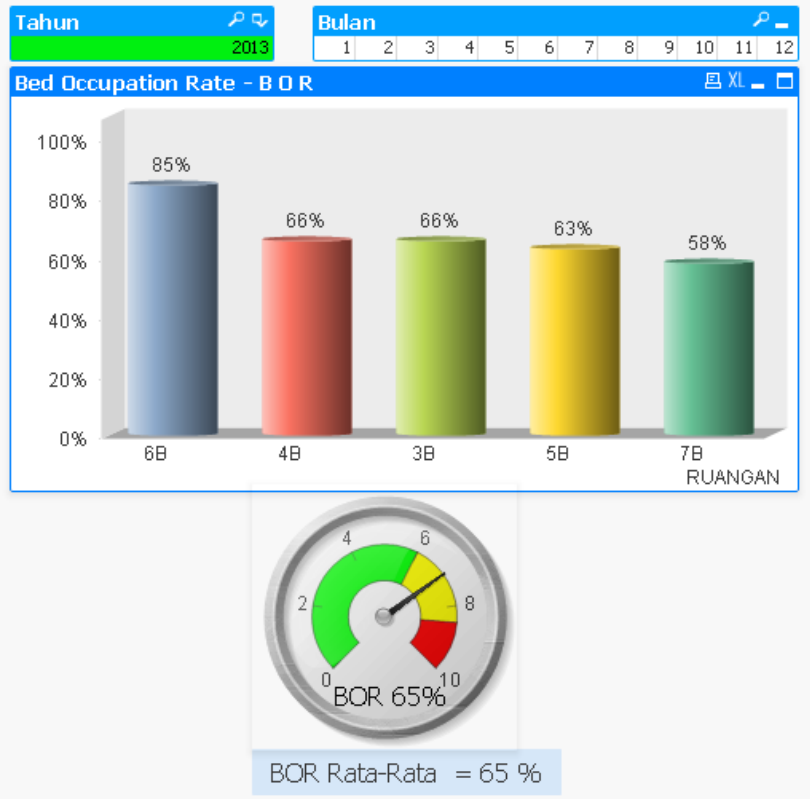

Gambar 2. TampilanAplikasi dashboard BOR

Dari gambar 2 diatas terlihat BOR rata-rata rumah sakit berada dalam kondisi normal. Namun pada ruangan $6 \mathrm{~B}$ perlu mendapat perhatian khusus karena telah mencapai lebih dari $80 \%$, sehingga perlu ditambah tempat tidurnya, sepanjang tempat tidur dan kondisi ruangan memungkinkan.

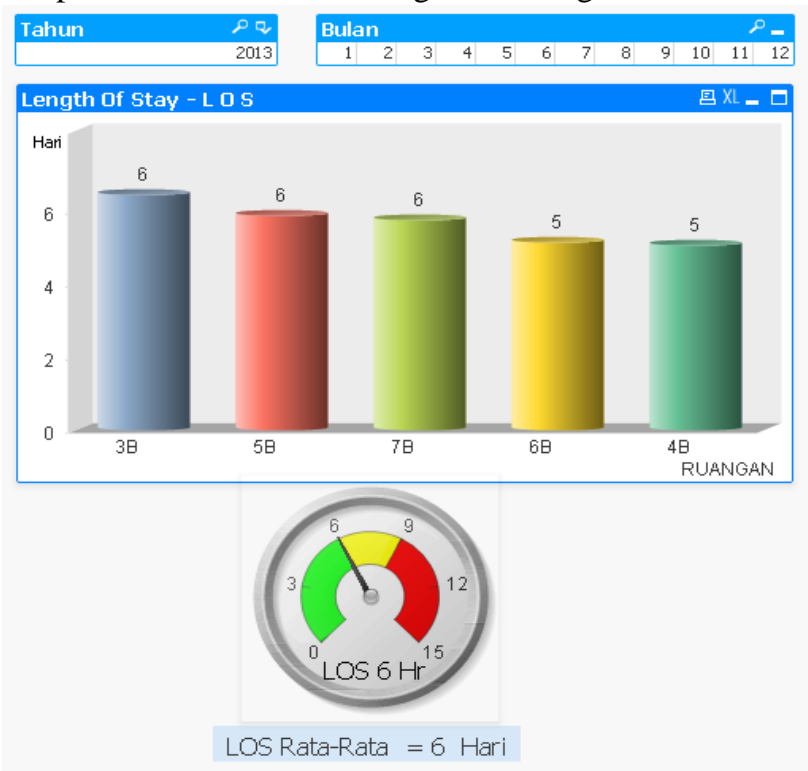

Gambar 3. Tampilan Aplikasi dashboard LOS 
JURNAL MEDIA INFORMATIKA BUDIDARMA

Volume 4, Nomor 3, Juli 2020, Page 495-502

ISSN 2614-5278 (media cetak), ISSN 2548-8368 (media online)

Available Online at https://ejurnal.stmik-budidarma.ac.id/index.php/mib

DOI 10.30865/mib.v4i3.2090

Dari gambar 3 diatas terlihat LOS rata-rata rumah sakit berada dalam kondisi normal.

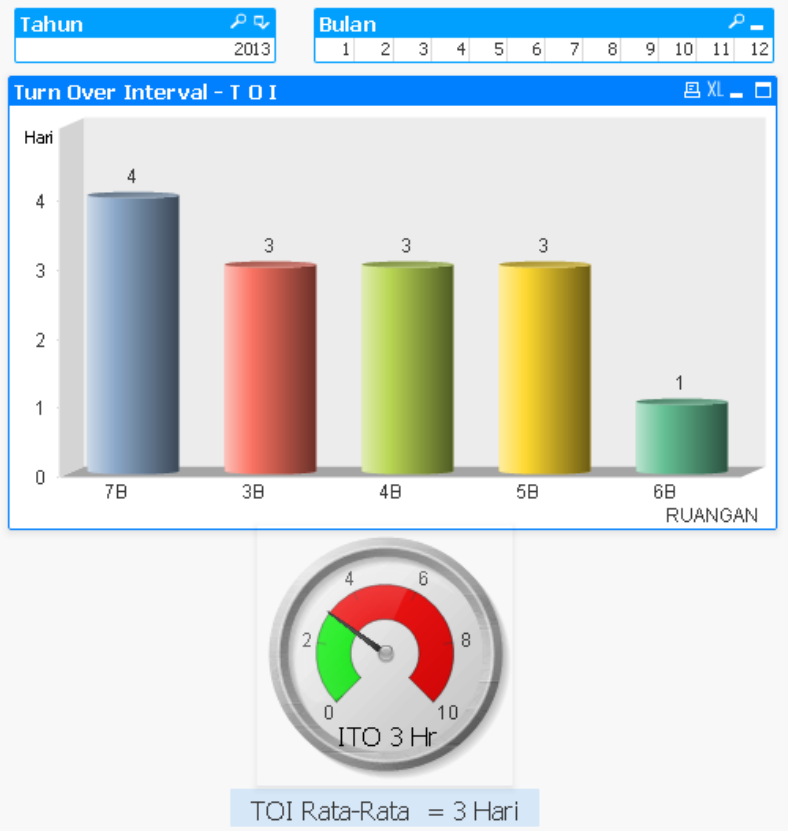

Gambar 4. Tampilan Aplikasi dashboard TOI

Dari gambar 4 diatas terlihat TOI rata-rata rumah sakit berada dalam kondisi normal.Namun pada ruangan 7B terlihat TOI terlalu tinggi, sedangkan BORnya rendah (gambar 2). Solusi terhadap masaalah ini bisa dilakukan dengan meningkatkan tatalaksana pekerjaan bagian penerimaan pasien dan pengaturan penempatan pasien di bangsal dalam upaya meningkatkan daya guna tempat tidur.

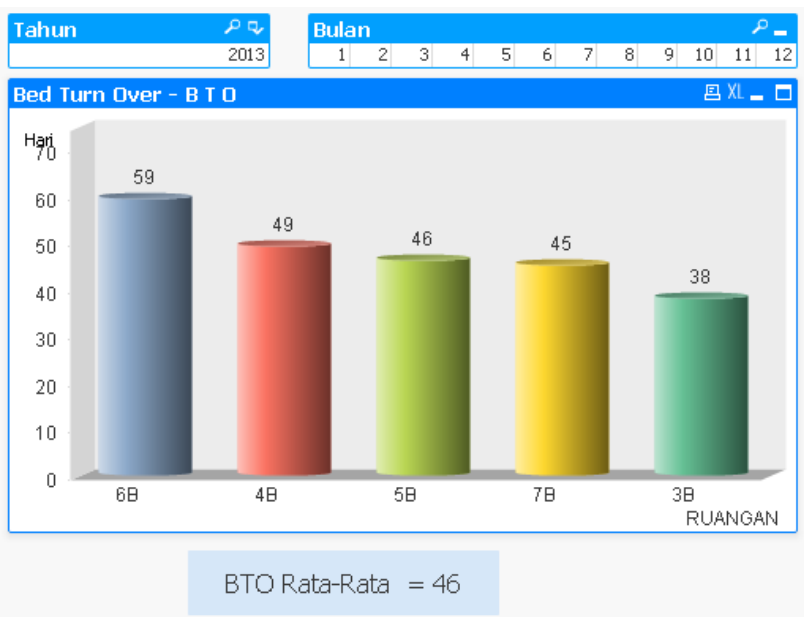

Gambar 5. TampilanAplikasi dashboard BTO

\section{KESIMPULAN}

Dari hasil implementasi diatas bisa terlihat bahwa kita bisa mentransform raw data menjadi informasi yang berarti menggunakan tools Business Intelligence. Business intelligence dapat melakukan data analisis yang dibutuhkan untuk pengambilan keputusan.

\section{REFERENCES}

[1] W. T, H. S, and L. L, "Evaluasi Kualitas Billing System Di Rumah Sakit Pku Muhammadiyah Yogyakarta," Universitas Gajah Mada, 2016.

[2] S. N.F, "Standart Akreditasi Rumah Sakit Dalam Meningkatkan Mutu Pelayanan Dan Keamanan," OSF, 2019.

[3] T. V.Y., R. G., and P. J., "Penerapan Sistem Informasi Rumah Sakit X Kota Manado Dalam Perencanaan Ketenagaan Dan Peralatan Medik," J. Kesmas, vol. 8, no. 6, pp. 36-48, 2019.

[4] N. Bahiyah and R. H. P. Sejati, "Business Intelligence Untuk Instansi Pelayanan Kesehatan:Manfaat Dan Peluangnya 


\section{JURNAL MEDIA INFORMATIKA BUDIDARMA}

Volume 4, Nomor 3, Juli 2020, Page 495-502

ISSN 2614-5278 (media cetak), ISSN 2548-8368 (media online)

Available Online at https://ejurnal.stmik-budidarma.ac.id/index.php/mib

DOI 10.30865/mib.v4i3.2090

Di Indonesia," in Seminar Nasional Informatika Medis (SNIMed), 2012, pp. 45-50.

[5] D. R. D. P. Medik, Pedoman Pengelolaan Rekam Medis Rumah Sakit di Indonesia, Revisi 1. Jakarta: Departemen Kesehatan RI Direktorat Jendral Pelayanan Medik, 2005.

[6] A. Johar, A. Vatresia, and L. Martasari, "Aplikasi Business Intelligence (Bi) Data Pasien Rumah Sakit M. Yunus Bengkulu Dengan Menggunakan Metode Olap (Online Analytical Processing)," Rekursif J. Inform., vol. 3, no. 1, pp. 12-22, 2015.

[7] M. R. Atsani, G. T. Anjari, and N. M. Saraswati, "Pengembangan Business Intelligence Di Rumah Sakit (Studi Kasus: Rsud Prof. Dr. Margono Soekarjo Purwokerto)," J. Telemat., vol. 12, no. 2, pp. 124-138, 2019.

[8] A. Maulana and D. A. N. Wulandari, "Business Intelligence Implementation To Analyze Perfect Store Data Using the OLAP Method," SinkrOn, vol. 3, no. 2, pp. 103-109, 2019.

[9] Sungkar, I. Ismail, and I. W. Mustafid, "Performance Dashboard pada Rumah Sakit Islam,” J. Sist. Inf. Bisnis, vol. 3 , pp. 123-128, 2011.

[10] W. H. Inmon, Building the Data Warehouse. USA: John Wiley \& Sons, Inc, 2010

[11] W. Giovinazzo, Objecy-Oriented Data Warehouse Design: Building a Star Scheme. Prentice Hall PTR, 2000.

[12] M. C, M. Abbey, and I. A, Oracle 8i : Data Warehousing. Osborn, 2001.

[13] H. B. and B. G, "Perancangan Aplikasi Business Intelligence Hasil Proses Belajar Mengajar," J. Eltek, vol. 11, no. 1 , pp. 83-95, 2017.

[14] M. García and B. Harmsen, Develop Business Intelligence applications with QlikView 11. Packt Publishing Ltd, 2012.

[15] J. P. New, D. Leather, N. D. Bakerly, J. McCrae, and J. M. Gibson, "Putting patients in control of data from electronic health records," Br. Med. J., 2018.

[16] C. H. Lee and H. . Yoon, Medical big data: Promise and challenges. Kidney Research and Clinical Practice, 2017. 